\title{
Civil Service Statistics 2008: a focus on gross
annual earnings
}

\section{SUMMARY}

This article presents a summary of annual Civil Service statistics for the year ending 31 March 2008. It compares trends over time with a particular focus on gross annual earnings broken down to different groups in the workforce such as men, women, ethnic minorities and those with a disability.

Previously produced by the Cabinet Office, responsibility for the collection and publication of Civil Service Statistics was transferred to the Office for National Statistics (ONS) in 2006. This transfer of responsibility was outlined in an 'In brief' article in the February 2007 edition of Economic \& Labour Market Review'.

\section{Key Findings}

- In 2008, the median gross annual earnings (excluding overtime or oneoff bonuses) for permanent full-time employees was $£ 22,520$, an increase of $£ 360$ (1.6 per cent) since the previous collection (2007) and $£ 3,910$ since 2003

- The gender pay gap, the difference in pay between male and female full-time permanent employees, in 2008 is 14 per cent

- The ethnicity pay gap, the difference in pay between white and ethnic minority employees is 0.8 per cent

- There is a 17 per cent pay gap between full-time and part-time (on a full-time equivalent basis) workers across the Civil Service in 2008

- The disability pay gap, the difference in median gross annual earnings between 'disabled' and ' non-disabled' civil servants, stands at 4 per cent

- The national identity pay gap, the difference in pay between British civil servants and those who declared a different national identity, is 2.2 per cent.

\section{Civil Service Statistics}

he most recent Civil Service Statistics were published on 20 January 2009 in the form of a First Release on the National Statistics website ${ }^{2}$. This paper will look at the key headline statistics that formed part of this publication. Attention will further focus on the differences in gross annual earnings between sub-groups of the Civil Service population. In so doing, the paper will highlight the wealth and breadth of statistics collected by the Annual Civil Service Employment Survey (ACSES) with the aim of increasing its usage across government as an informative data source.

This article is presented in five parts. First, a brief discussion is presented to provide context with regards to the development of Civil Service Statistics as an ONS output and how it has evolved from the previous Mandate ${ }^{3}$ collection, which was developed and managed by Cabinet Office. Second, an overview of the survey methodology process is presented, in order to explain to those unfamiliar with the survey and its outputs, how the data are collected; a brief section will also detail how the survey should be viewed over time from a statistical standpoint. Third, the paper will consider the notion of diversity across the Civil Service and the policies that have been introduced in an attempt to achieve a more diverse and representative workforce. Fourth, the paper will consider the notion of gross annual salary before shifting focus to key diversity statistics such as gender, age, ethnicity, disability, national identity, working pattern and region of employment. Lastly a synthesis is provided, together with pointers to further research that may be undertaken to improve understanding of the Civil Service workforce.

\section{Data sets: QPSES and ACSES}

In 2005 ONS undertook a successful development programme to improve the quality of public sector employment (PSE) statistics and related outputs. As part of this work, definitions for public sector employment across all departmental 
statistics were agreed and a single definitive set of quarterly PSE estimates introduced. A direct outcome of this development programme was that a new Quarterly Public Sector Employment Survey (QPSES) was established to fill the gap not met by other sources and to improve the accuracy and coverage of estimates. ONS now publishes (as National Statistics) official public sector employment estimates each quarter, in the form of a First Release ${ }^{4}$, approximately 11 weeks after the period to which they refer.

A secondary effect of the development of QPSES, was that it improved the consistency across government of official employment statistics, especially those directly associated with the public sector. It also became possible to rationalise the number of collections from public bodies.

One of the existing surveys, chosen to be part of the rationalisation framework was the Mandate Collection, which had previously been administered by the Cabinet Office. The Cabinet Office had conducted the Mandate Collection on a 6-monthly basis. With the introduction of the quarterly survey this collection became annual and was transferred to ONS.

Since 2006, the Office for National Statistics has been responsible for the collection and publication of annual Civil Service Statistics. Civil Service Statistics are sourced from the Annual Civil Service Employment Survey (ACSES) which, following a development programme in 2007, replaced the Mandate collection.

\section{Comparison over time}

Information about staffing in the Civil Service has been collected and published across government since 1950, and statistics are available from the Civil Service Statistics website back to $1970^{5}$. Since 2007 Civil Service Statistics have been compiled from a single source, the ACSES. Prior to 2007, government departments supplied information either via the Mandate collection or by a departmental return.

Broadly, the survey methodology for ACSES is very similar to the Mandate collection. However the development programme initiated two key improvements. First, ACSES makes use of a uniform method of collection for all government departments whereas previously, as mentioned, two collection tools were utilised as part of the Mandate collection:

- The Mandate collection accounted for approximately 85 per cent of the Civil Service and comprised (as is now the case for ACSES) a comprehensive anonymous data set generally extracted from the human resources systems of government departments and their agencies;

- For historical reasons some departments were not considered to be 'Mandate reliant' and supplied only summary tables instead. These were called Departmental Returns and covered only a limited subset of (aggregated) data.

Second, ACSES offers flexibility of collection. In consultation with the Cabinet Office and other government departments the content of the survey is continuously updated and reviewed. Each year, variables may be removed or added from the survey as policy requirements change, for example, 'Marital Status' was removed prior to the 2007 data collection. This ensures burdens on departments are kept to a minimum, and that ACSES is as responsive and flexible a survey tool as possible in order to meet the changing demands and priorities of government.

The Mandate collection accounted for approximately 85 per cent of the Civil Service. In contrast, the ACSES accounts for 100 per cent of the Civil Service population.

\section{Collecting frame - ACSES}

The ACSES collects detailed statistics on individuals, with Civil Service status, who work within Civil Service government departments. An Excel spreadsheet, along with a Specification Guide, is sent to the 126 (as of 31 March 2008) Civil Service departments and their agencies across Great Britain.

Once the information supplied by a government department or agency has been confirmed the data are amalgamated into a larger file (data from all government departments and agencies are merged) from which various analyses of the figures are published.

The findings from the ACSES survey are an amalgamation of data reported to ONS by each government department and agency. As such, this article attempts to interpret some of the key stories and trends with respect to one specific variable, gross annual earnings.

\section{Diversity across the Civil Service}

The term diversity encompasses differences in ethnicity, age, gender, disability, and national identity as well as other identifying features.

Across government, positive action has sought to increase the diversity of the Civil
Service workforce. On 1 November 2005, Sir Gus O'Donnell unveiled a 10-Point Plan ${ }^{6}$ with the intention of moving to a more representative Civil Service. The Plan introduced a major programme of change aimed at achieving a diverse workforce at all levels of the Civil Service. It reached further than previous work by embedding diversity as a key measure of performance for Permanent Secretaries. The core tenet of the plan was "to improve delivery of services for everyone in society through achieving a truly diverse Civil Service workforce at all levels, including the most senior ${ }^{6 "}$.

It also set the following targets to be achieved by 2008 :

- 37 per cent of the Senior Civil Service to be women (31 per cent as of 31 March 2008 ${ }^{7}$ );

- 4 per cent of the Senior Civil Service to be from minority ethnic backgrounds (4.3 per cent as of 31 March 20087);

- 3.2 per cent of the Senior Civil Service to be disabled people (3.4 per cent as of 31 March 20087).

Keen to build on the perceived success of the 10-point plan the Cabinet Office launched, in July 2008, their next strategy for improving diversity throughout the Civil Service. 'Promoting Equality, Valuing Diversity: A Strategy for the Civil Service ${ }^{8}$ builds on previous achievements attributable to the 10-point plan by further encouraging a drive to fostering mainstream equality and diversity into every aspect of business. It is also a framework of commitments that will help the Civil Service fulfil the new single public equality duty under the Government's new vision for equality; Framework for a Fairer Future - the Equality Bills.

The rest of this article will expose the diverse nature of the Civil Service with a particular focus on gross annual earnings. While considering this research, it is important to acknowledge that although the following statistics provide a useful comparison of sub-groups' earnings they do not reveal differences in the rates of pay for comparable jobs. The best measure of this is to take account of the responsibility level of the job held by individuals across the different diversity classifications; however this is only one facet of a very complex issue.

All of the following diversity statistics, with the exception of those on working pattern, are based on the records of permanent full-time civil servants (unless otherwise stated). 


\section{Gross median annual earnings}

ACSES collects the gross salary of every civil servant. Gross salary is the annual salary, inclusive of basic pay (including consolidated performance pay) and payrelated allowances such as regional and skills allowances. It does not include bonuses. In 2008, the gross salary of 99 per cent of civil servants was reported by their respective department or agency.

The earnings statistics presented in this article are based on the median rather than the mean. The median is the value below which 50 per cent of employees fall. It is preferred, by ONS, over the mean for earnings data as it is influenced less by extreme values and because of the known skewed distribution of earnings.

Pay across the Civil Service for a permanent full-time employee has increased over the last five years. In $2008^{9}$, the median gross annual earnings (excluding overtime or one-off bonuses) for permanent full-time employees was $£ 22,520$, an increase of $£ 360$ since the previous collection (2007) and $£ 3,910$ since 2003 .

Figure 1 shows the distribution of base pay in the Civil Service. It shows that the majority (60 per cent) of permanent fulltime civil servants earn less than $£ 25,000$ per annum.

\section{Gender}

In 2008, just over half (53 per cent) of all permanent employees were women. Within the Civil Service the representation of women has been increasing year on year since 1991 and women have accounted for more than half of civil servants since $2001^{10}$.

Based on data collected as part of the 2008 ACSES, median gross annual earnings for male full-time permanent employees were $£ 24,130$ and for females, $£ 20,750$. By analysing the difference in annual earnings for male and female full-time permanent employees over the past five years, two trends are particularly evident (Figure 2).

First, the overall gender pay gap has decreased over time - the median gross annual earnings of male and female fulltime permanent employees have moved closer together. In 2003, the gender pay gap was 22 per cent compared to a 14 per cent difference between the annual earnings of males and females in 2008. Second, women's annual earnings are rising at a faster rate than men's. In 2003, permanent full-time women earned $£ 16,600$, this compares to a median income for permanent full-time female employees in 2008 of $£ 20,750$; an increase of 25 per cent compared to an increase of 14 per cent for males over the

Figure 1

Percentage of Civil Service permanent full-time staff in salary band, March 2008

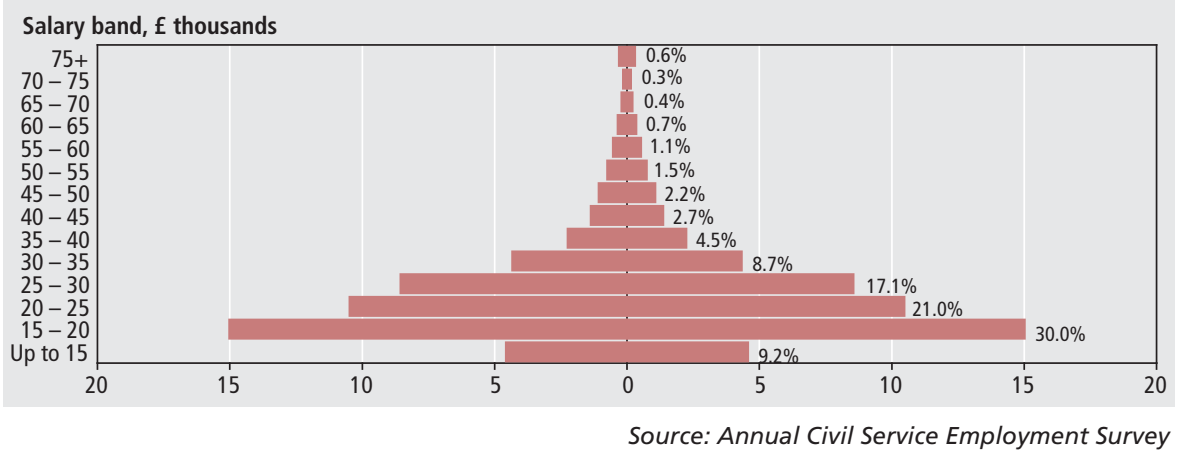

Figure 2

Median gross annual earnings, permanent, full-time, 2003-2008

f

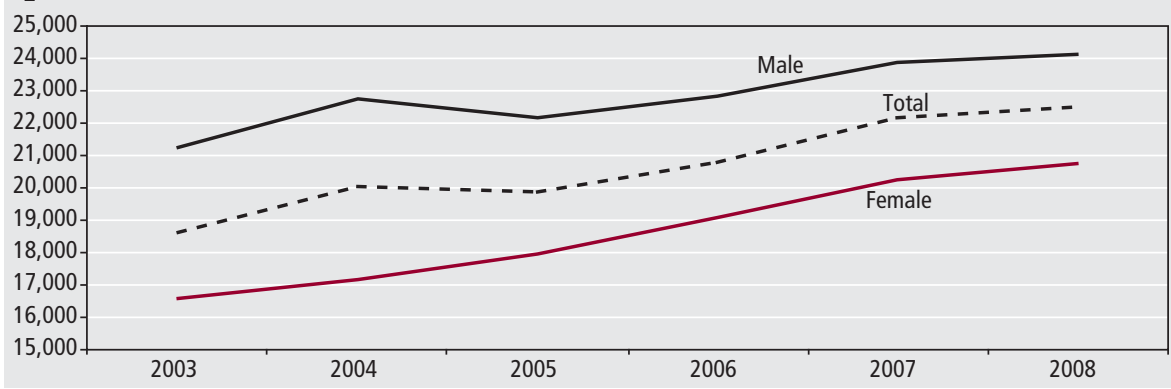

Source: Annual Civil Service Employment Survey

Figure 3

Median annual gross salary of full-time civil servants by gender and
responsibility level, permanent, March 2008

f

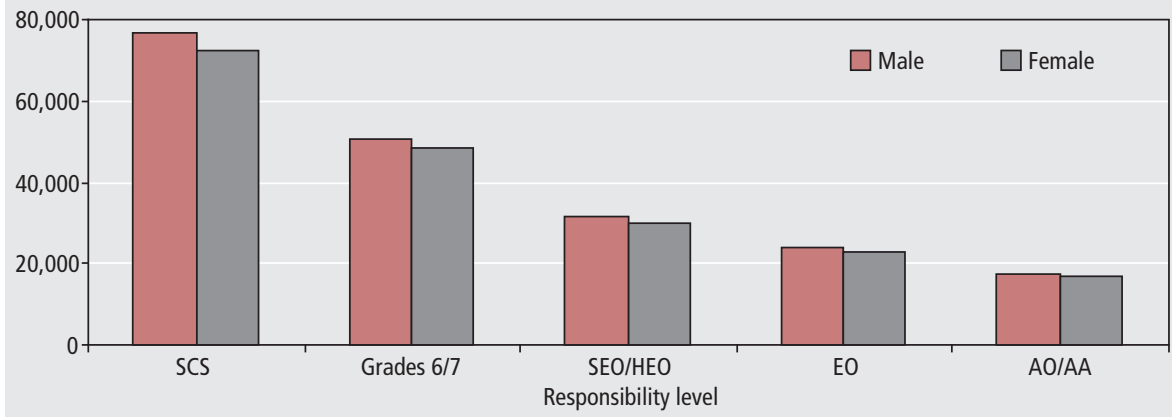

Source: Annual Civil Service Employment Survey

same period. When responsibility level is taken into account, the gender pay gap for males and females across the recognised responsibility levels diminishes to between 4 and 6 per cent (Figure 3).

When age is taken into account it appears that a difference in pay, albeit slight, exists for males and females aged less than 30 years. A 4.6 per cent difference is evident between males aged less than 30 years of age $(£ 17,980)$ and females of the same age $(£ 17,150)$. This is in contrast to males and females aged 30 years and over where males earn on average $£ 25,210$ and females earn $£ 21,670$ - this also equates to a difference in pay of 14 per cent.

\section{Ethnicity}

When joining the Civil Service, employees are asked to declare their ethnic

background. For the purposes of the ACSES collection this information is then allocated to one of 16 categories that best describes the individuals' ethnic background. Civil servants are given the option of 'not declaring' their ethnicity. The ethnicity of 21 per cent of permanent employees in 2008 data was 'not declared' or 'not known'.

In 2008, the proportion of permanent employees in the Civil Service who declared themselves as being from a minority ethnic background (i.e. Asian, Black, Chinese, 
Table 1

Civil Service employment, median earnings by ethnicity and responsibility level, 31 March 2008,

Full-time permanent employees

\begin{tabular}{|c|c|c|c|c|c|c|c|c|}
\hline Responsibility level ${ }^{3,4}$ & White & Asian & Black & Chinese & Mixed & Other ethnicity & $\begin{array}{r}\text { Not Declared or } \\
\text { non-response }\end{array}$ & All employees \\
\hline \multicolumn{9}{|l|}{ Senior Management } \\
\hline Senior Civil Service & 75,390 & 73,980 & 75,950 & .. & 73,320 & 75,090 & 77,510 & 75,670 \\
\hline \multicolumn{9}{|l|}{ Other Management } \\
\hline Grades 6 and 7 & 49,560 & 49,470 & 47,740 & 49,850 & 48,730 & 50,050 & 50,000 & 49,610 \\
\hline Senior and Higher Executive Officers & 31,230 & 30,880 & 31,060 & 30,650 & 31,020 & 31,020 & 31,350 & 31,350 \\
\hline Executive Officers & 22,910 & 23,990 & 24,440 & 23,300 & 22,970 & 23,740 & 23,990 & 23,470 \\
\hline \multicolumn{9}{|l|}{ Administrative } \\
\hline Administrative Officers and Assistants & 17,370 & 17,740 & 19,380 & 17,420 & 17,360 & 17,790 & 16,900 & 17,370 \\
\hline Not reported & 26,700 & 20,940 & .. & .. & 18,690 & .. & 24,740 & 26,150 \\
\hline All employees & 22,670 & 21,800 & 23,210 & 22,130 & 22,560 & 23,500 & 22,110 & 22,520 \\
\hline
\end{tabular}

Notes:

Source: Annual Civil Service Employment Survey

1 Numbers are rounded to the nearest ten, and numbers based on less than five individuals are represented by "..".

2 Salaries in this table represent actual annual gross salaries rounded to the nearest ten.

3 With the exception of the Senior Civil Service, government departments have delegated pay and grading. For statistical purposes departments are asked to map their grades to a common framework by responsibility level.

4 This table shows staff in their substantive responsibility level unless on temporary promotion in which case staff are recorded at the higher responsibility level.

Mixed and Other) was 8.5 per cent, this compares to 6.0 per cent in 2001. Employees from minority ethnic backgrounds are more highly represented in Executive Officer $(9.6$ per cent) and administrative grades (8.9 per cent). This compares with 4.3 per cent for the Senior Civil Service, the least ethnically diverse grade.

Table 1 displays the median earnings of full-time permanent employees by ethnicity and responsibility level. White full-time permanent employees earn less than the median income for 'all employees' (includes those civil servants who chose not to declare their ethnicity status) across all responsibility levels; however the median income for all white full-time permanent employees $(£ 22,670)$ is greater than the median income for all full-time permanent employees $(£ 22,520)$. Fulltime permanent Asian employees have the lowest median earnings as a whole population $(£ 21,800)$.

There is a further contrast in the gross annual salary of male and female, white and ethnic minority civil servants. Ethnic minority males $(£ 22,960)$ earn 6.2 per cent less than white males ( $£ 24,490)$, whereas ethnic minority females $(£ 22,160)$ earn 7.3 per cent more than their white $(£ 20,530)$ colleagues.

The ethnicity pay gap, the difference in pay between white and ethnic minority employees is $0.8 \%$. When consideration is given to responsibility level it is apparent that ethnic minority employees at the lower responsibility levels (Executive Officer and administrative) earn more than their white colleagues.

\section{Age}

The age structure of the Civil Service has changed markedly over time; for example, the median age of civil servants increased from 38 to 44 years between 1997 and $2008^{10}$. In 2008, 56 per cent of permanent employees in the Civil Service were aged between 30 and 49 years. Just under onethird ( 30 per cent) were aged 50 years and over and only 14 per cent under 30 years (this compares to 20 per cent in 1997).

As Figure 4 clearly demonstrates the median income for full-time employees in the Civil Service changes with respect to the age of the civil servant. Median earnings are lowest for civil servants aged 16 years $(£ 12,590)$; however the rate of increase in median pay is greatest for civil servants aged 16 to 30 years. The majority of civil servants, according to Figure 4 can expect to reach their peak in gross annual earnings when aged 52 years $(£ 25,210)$. After this point in time median earnings in general fall with the median for those aged 65 years and over being $£ 18,730$.

There is a contrast between the median gross annual earnings of 16-49 year olds

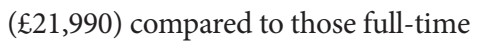
permanent civil servants aged $50+$ years $(£ 23,990)$. This can largely be explained by the presence of older civil servants in more senior positions across the Civil Service. In 2008, approximately half (49 per cent) of the Senior Civil Service were aged 50 years and over. This compares with 30 per cent of civil servants employed at administrative grades. It is important to acknowledge, however, that age is often linked to experience and experience to reward, which may explain this difference in median earnings.

The age pay gap - the difference in gross annual earnings between civil servants aged less than 50 years and those aged 50 years and over is 8.3 per cent.

\section{Figure 4}

\section{Civil Service employment, median earnings by age, March 2008}

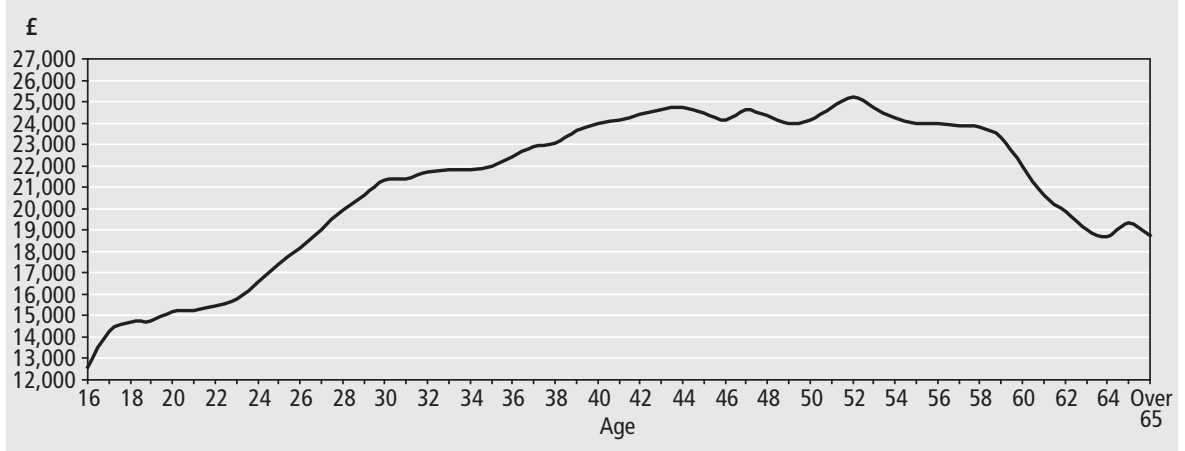

Source: Annual Civil Service Employment Survey 


\section{Figure 5}

\section{Civil Service employment, employees working part-time, 1997-2008}

\section{Per cent}

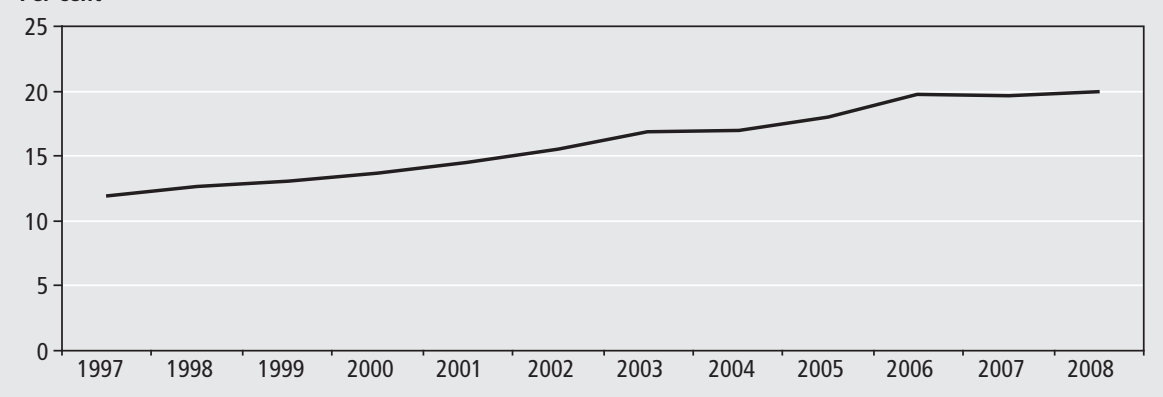

Source: Annual Civil Service Employment Survey

\section{Working Pattern}

Over time flexible working patterns have become increasingly common across the Civil Service. Figure 5 demonstrates that the number of permanent civil servants who work part-time has increased from 12 per cent in 1997 to 20 per cent in 2008. In 2008, around 80 per cent of permanent employees worked full-time, with the remaining 20 per cent working part-time. Just over half (53 per cent) of all permanent employees were women, with women making up 88 per cent of the part-time workforce.

The median gross annual actual earnings for permanent part-time workers is $£ 13,380$. For males it is $£ 13,910$ and for females $£ 13,240$, a difference of 4.8 per cent. However, the analysis does not take into account the number of hours worked by individual male and female civil servants. When the gross annual earnings of parttime employees is converted into the earnings that a part-time employee would earn if they were working full-time, the difference in the annual earnings between male $(£ 19,950)$ and female $(£ 18,720)$ permanent employees increases to $6.2 \mathrm{per}$ cent.

When compared to the annual gross salary of full-time workers it is evident that part-time workers, even when their salaries are converted to a full-time equivalent status earn less than full-time employees. There is a 17 per cent pay gap between full-time and part-time (on a full-time equivalent basis) workers across the Civil Service in 2008.

\section{Disability}

In 2008, the proportion of permanent civil servants recorded as 'disabled' was 6.6 per cent. This is over double the proportion of civil servants declaring themselves as disabled in 2001 (3.1 per cent $)^{11}$. The proportion of employees with a declared disability was highest at the lower responsibility levels -7.5 per cent of employees at administrative grades compared with 3.4 per cent of the Senior Civil Service and 4.2 per cent of Grades $6 / 7$. The disability pay gap, the difference in median gross annual earnings between 'disabled' and 'non-disabled' civil servants stands at 4 per cent. When analysis is undertaken across the recognised responsibility levels, the median income of full-time permanent 'disabled' civil servants is higher than that of 'non-disabled' civil servants, apart from the Senior Civil Service where there is a 0.6 per cent difference in favour of non-disabled civil servants.

\section{National identity}

In 2008, of those where nationality is reported (83 per cent of permanent employees), 37.0 per cent of permanent Civil Servants declared themselves as British or Mixed British. Employees alternatively declared themselves as English (46.4 per cent), Irish ( 0.9 per cent), Scottish (8.9 per cent), and Welsh (5.0 per cent). A further, 1.9 per cent recorded another national identity (Figure 6).

In 2008, those full-time permanent employees who declared a 'British' national identity earned on average $£ 22,810$, this compares with civil servants who declared themselves as Irish who earned on average $£ 23,990$ - the highest amount across all national identities and Welsh civil servants who earned the least, $£ 21,240$.

The national identity pay gap, the difference in pay between British civil servants and those who declared a different national identity in 2008 is $2.2 \%$.

\section{Region}

The last 20 years have seen a reduction in the proportion of permanent civil servants located in London and the South East. In 2008, 16 per cent of UK based civil servants worked in London. Nearly, three-quarters (74 per cent) of civil servants worked outside London and the South East, with 9 per cent based in Scotland and 7 per cent based in Wales.

The regional pay gap, the difference in pay between full-time employees in London $(£ 28,250)$ and those working elsewhere in a known location $(£ 21,200)$ in the United Kingdom is 25\%. When considering differences in pay for Civil Service employees across regions it is vitally important to take account of geographical monetary payments, for instance, 'London Weighting' which impact on the amounts received by employees.

\section{How do Civil Servants Compare?}

In line with the rest of the UK labour market the pay distribution in the Civil Service is skewed to the lower levels (Figure 1). However, in comparison with data collected as part of the Annual Survey of Hours and Earnings (ASHE) ${ }^{12}$ it would appear that civil servants are paid less than their counterparts in the private and wider public sector. Whereas the gross annual median earnings for a full-time permanent employee in the Civil Service in 2008 were $£ 22,520$ the median gross earnings of fulltime employees in the private sector was $£ 24,450^{13}$ and in the public sector (includes those employed in the Civil Service) the figure was $£ 26,660^{13}$.

\section{Figure 6}

\section{National identity of permanent civil servants, March 2008}

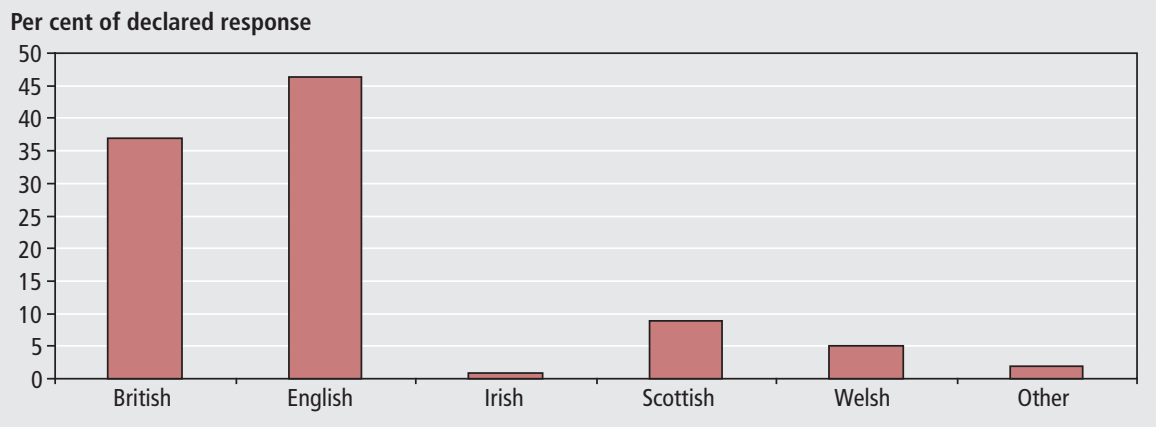


Table 2

\section{Civil Service pay gaps, 31 March 2008 1,2}

Permanent employees

Per cent

\begin{tabular}{lrrr}
\hline & & \multicolumn{2}{c}{ Across responsibility levels (per cent) } \\
& Pay Gap (per cent) & Min & Max \\
\hline Gender $^{3}$ & 14 & 4 & 6 \\
Ethnicity $^{4}$ & 1 & 1 & 5 \\
Age $^{5}$ & 8 & 3 & 11 \\
Working Pattern $^{6}$ & 17 & 1 & 5 \\
Disability $^{7}$ & 4 & 1 & 3 \\
National Identity $^{8}$ & 2 & 0 & 3 \\
Region $^{9}$ & 25 & 3 & 16 \\
\hline
\end{tabular}

Notes:

Source: Annual Civil Service Employment Survey

1 Numbers are rounded to the nearest ten, and numbers less than five are represented by "..".

2 Salaries in this table represent actual annual gross salaries rounded to the nearest ten.

3 Difference in pay between full-time male and female employees.

4 Difference in pay between full-time white and non-white employees.

5 Difference in pay between full-time employees aged 50 years and above and 16 to 49 years.

6 Difference in pay between full-time and part-time employees, based on median full-time equivalent earnings.

7 Difference in pay between full-time disabled and non-disabled employees.

8 Difference in pay between full-time British employees and those declaring an other national identity.

9 Difference in pay between full-time employees working in London and the rest of the UK

\section{Conclusions}

The purpose of this article is to draw attention to the value of the ACSES as a resource and also the underlying differences in gross annual salary evident when analysis is carried out at a micro-level through the use of diversity statistics across the Civil Service.

At all times it is important to consider differences that exist among sub-groups. By understanding differences that currently exist it is possible for future planning to be directed and purposeful in its approach. This article takes an initial look at the differences across the Civil Service. In doing so, it draws attention to where further research might be undertaken to understand and further examine why differences in gross annual salary exist for different groups of Civil Servants. A continuation of this work would be to monitor changes to these statistics over time.

The majority of the statistics presented in this article are based on a snapshot of data, a collection undertaken with reference to a single point in time and thus do not show changes that have unfolded over the last decade. For instance, analysis of gross annual earnings by gender for the last five years clearly indicates that the situation has altered.

Table 2 presents the differences in pay for sub-groups of the Civil Service. The table shows that the greatest disparity in pay is between full-time permanent civil servants based in different parts of the United Kingdom (25 per cent). However, the table also draws attention to the effect of taking account of responsibility level. It highlights, firstly, that when responsibility levels are taken into account, differences in pay reduce markedly for all subgroups. Secondly, it further highlights the importance of considering a full range of factors, of which responsibility level is just one, before analysing differences between sub-groups and gross annual earnings.

While this analysis is informative it does not take account of differences in qualifications, choice of occupations (other than that the employees concerned are all civil servants), career plans and lifestyle choices individuals make throughout their lives. Nevertheless, it does perform an important function with regards to identifying differences that exist across the Civil Service and also the diverse nature of the Civil Service workforce.

\section{Notes}

1 www.statistics.gov.uk/elmr/02_07/ downloads/ELMR_Feb07.pdf

2 www.statistics.gov.uk/pdfdir/cs0109.pdf

3 http://beta.civilservice.gov.uk/about/ who/statistics/archived-reports.aspx

4 www.statistics.gov.uk/pdfdir/pse1208. pdf

5 http://beta.civilservice.gov.uk/about/ who/statistics/archived-reports.aspx

6 www.civilservice.gov.uk/iam/ diversity/10point/index.asp

7 SCS diversity statistics are officially sourced from the SCS database, compiled by ONS for Cabinet Office. This is because ACSES includes some officials at SCS level equivalent as well as 'Senior Civil Servants'. ACSES does however provide a useful tool for comparison.

8 http://beta.civilservice.gov.uk/about/ who/diversity/achieving.aspx

9 Figures for 2008 refer to a reference point of 31 March.

10 http://beta.civilservice.gov.uk/ news/2009/february/civil-servantseconomic-downturn.aspx $\# 0$

112008 disability figures is as a percentage of all those with a known disability status. Before 2007 is a percentage of all staff.

12 www.statistics.gov.uk/pdfdir/ashe1108. pdf

13 Annualised median gross weekly pay of full-time employees.

\section{CONTACT}

国elmr@ons.gsi.gov.uk 